\title{
TO DEVELOP A WELD TEMPERATURE MEASURING SYSTEM
}

\author{
Akash Sinha ${ }^{1}$, Rahul Kumar ${ }^{2}$, Samsh Niyaz $^{3}$, Pradeep Khanna ${ }^{4}$ \\ ${ }^{1}$ Student, Netaji Subhas University of Technology \\ ${ }^{2}$ Student, Netaji Subhas University of technology \\ ${ }^{3}$ Student, Netaji Subhas University of Technology \\ ${ }^{4}$ Associate Professor, Department of MPAE, Netaji Subhas University of Technology
}

\begin{abstract}
Temperature distribution during any welding process holds the key for understanding and predicting several important welding attributes like heat affected zone, microstructure of the weld, residual stress, and distortion during welding. The metal-inert gas welding temperature in the heat affected zone was measured with the help of $k$-type thermocouple wire. The thermocouples junctions were made with the help of a soft arc of carbon arc welding. These junctions (hot junctions) were then embedded into the workpiece through brazing at progressively increasing distance from the weld line so as to record the variation of temperature with respect to distance from weld center line. The thermocouple wire was connected to a circuit at the Sunrom thermocouple amplifier. The temperature was measured on Arduino serial plotter. The temperature found during MIG welding were in good agreement with the expected temperature at the specified distance for a particular set of conditions.
\end{abstract}

Keywords: - Heat affected zone, temperature distribution, thermocouple, Microcontroller. -***

\section{INTRODUCTION}

Gas metal arc welding is one of the most commonly used general purpose arc welding process, because of its versatility, ease of automation and capability of all position welding is a preferred choice in fabrication, automotive, aerospace and ship building industries [1,2]. Like any arc welding process, this process too ends up subjecting the weldment to rapid heating and cooling cycles. During welding process, the material exposed with heat flux causes phase change of the metal during melting [3]. The manner of heat distribution during welding depends on types of welding process, selection of material, material being welded and method of welding. The manner of heat flow and thus the distribution pattern of temperature in the weldment affects many important aspects like generation of residual stresses, the extent and type of microstructural changes thermally distortion and mechanical properties of the welding. The correct knowledge of these aspects is of extreme importance so that behavior of weldment can be well predicted.to achieve this it is necessary to estimate correct temperature at the location of interest in the weldment. In the present work an attempt has been made to develop a system that can provide a low cost and simple solution of determining temperature of different location of weldment by using simple and cost-effective components. A $\mathrm{k}$ type thermocouple wire has been used to sense the temperature of the weldment at different points, this data is then converted to output voltage signal after amplification corresponding to the value of temperature. The calibration has already been affected with the help of Arduino Nano which gives the real time output on a temperature to time scale. The information from this graph can be utilized to carry out further investigative on the above aspects.

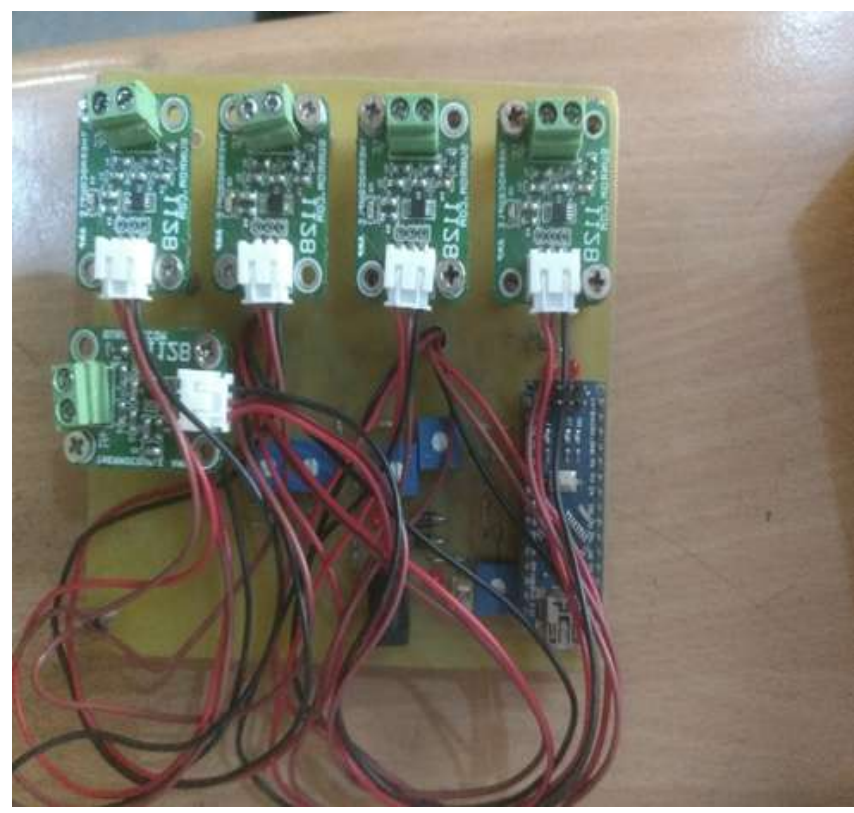

Fig 1: Electronic circuit of system

\section{EXPERIMENTAL SETUP}

The experimental setup consists of MIG welding power source with flat VI characteristics and rated capacity of $400 \mathrm{~A}$ at $60 \%$ duty cycle. The welding was carried out on a mechanised carriage unit with a sliding table whose speed can be varied from $0-50 \mathrm{~m} / \mathrm{min}$. A machine welding torch was used for purpose by mounting it on radial arm with the facility of vertical and horizontal movements of the same to ensure correct positioning and correct arc lengths. A gas welding unit was also used to braze the thermocouple hot junction in the workpieces. A carbon arc welding unit was used to fuse hot junction wires. 


\section{PREPARATION OF SPECIMEN}

The test specimen is prepared from C 45 steel-6mm thick, $150 \mathrm{~mm}$ long and $135 \mathrm{~mm}$ wide. Bead on plate technique was used for the present purpose. A centreline was marked along length of workpiece. Five holes $(6 \mathrm{~mm}$ diameter and $3 \mathrm{~mm}$ deep) were then drilled at progressively increasing distance from marked centreline. Thermocouple wires were then fused at their hot junction to a fine spot with the help of a soft carbon arc as shown in figure 2. These spotted hot junctions were then brazed in the drilled holes by using oxyacetylene gas frame as shown in figure 2 .

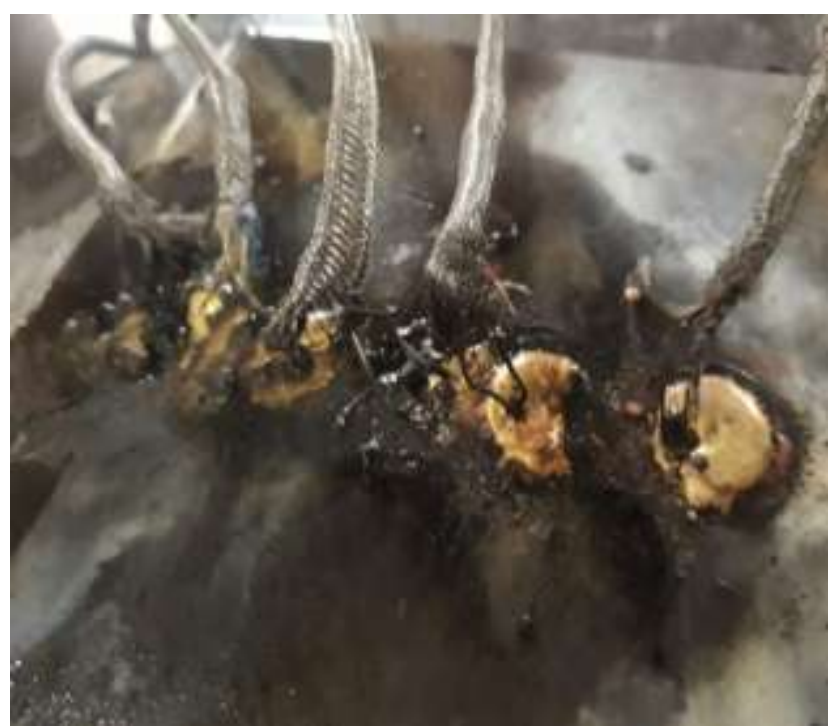

Fig 2: Thermocouple wires connected to the specimen.

\section{CONDUCTION OF EXPERIMENT}

The prepared specimen was placed on welding fixture such that the bottom side of weld piece is roughly $80 \mathrm{~mm}$ above weld table to facilitate space for thermocouple bar as shown in figure. The cold junction of these thermocouple wires was connected to five channels temperature logging system as shown in figure 3 which was developed using Arduino board. The output from this control board was connected to a monitor screen to record real time temperature data from the welding.

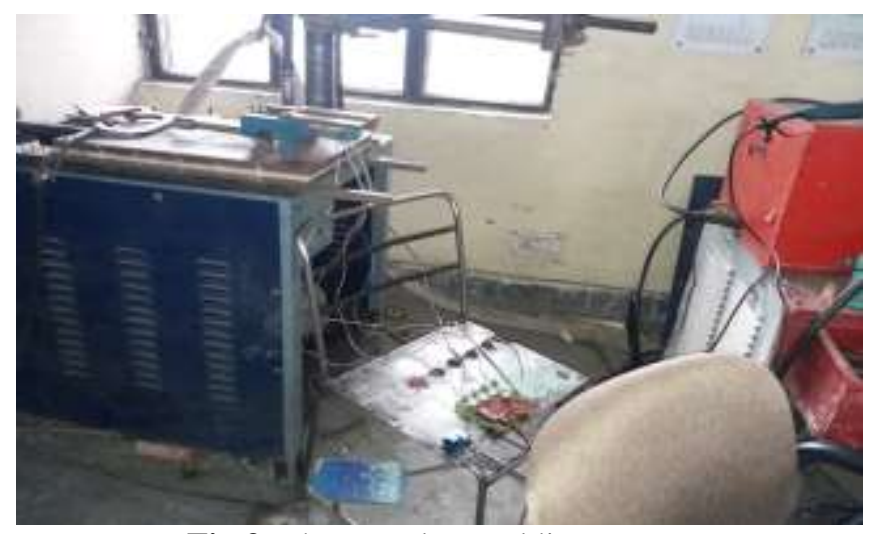

Fig 3: The complete welding set up
A weld bead then was deposited at following parameters:

Wire feed rate $=1.25 \mathrm{~m} / \mathrm{min}$

Voltage $=18$ Volt

$\mathrm{NPD}=15 \mathrm{~mm}$

Welding speed $=31.57 \mathrm{~cm} /$ minute

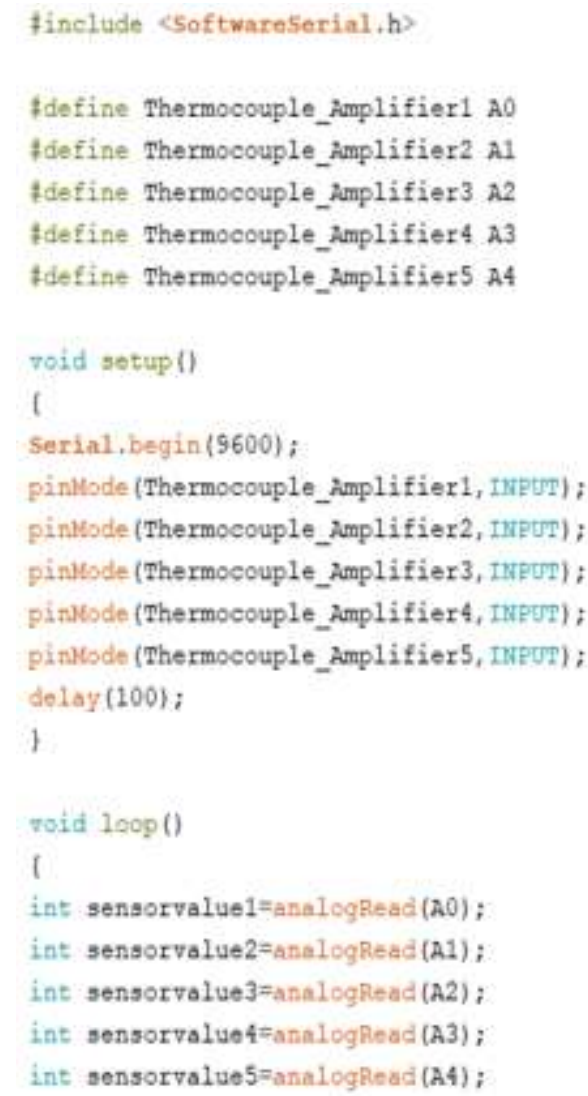

Fig 4: Part of the working code

Inert gas used is Argon

\section{EXCREPT OF WORKING CODE}

The part of Arduino code used to obtain temperature v/s time graph is shown in figure-4.

\section{RESULT}

The result obtained in the form of a graph plotted on the basis of real time data obtained from thermocouple junctions attached to the bottom side of the weld piece is shown in fig.5. 


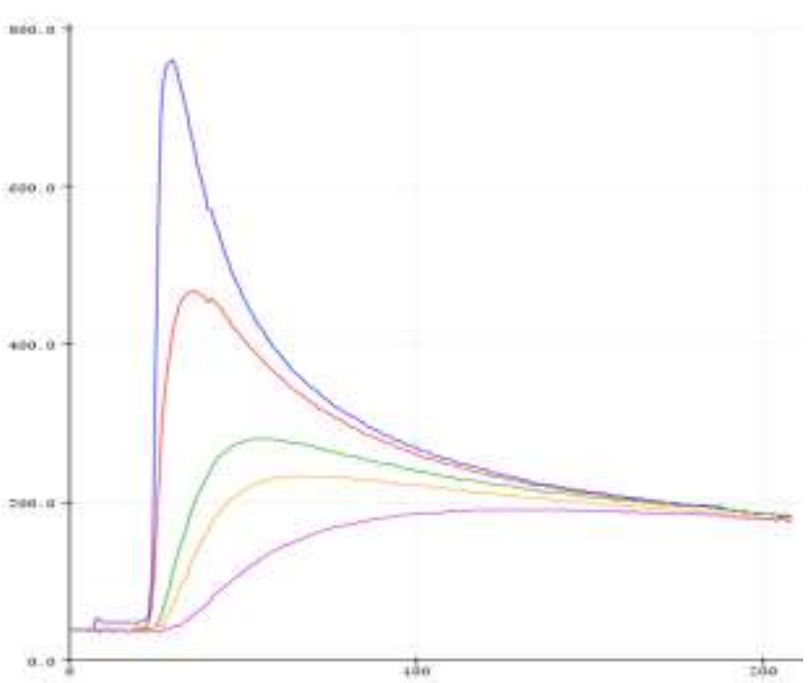

Fig 5: Temperature vs Time plot

It is evident from the figure that the junction attached exactly below the weld center line recorded the highest temperature whereas the lowest temperature peak was registered by the farthest thermocouple. The above diagram can be used to plot the weld isotherms which can further be used to estimate the cooling rates along the direction of interest. These cooling rates can then be superimposed on the TTT curve for the weld material to estimate the kind of metallurgical changes occurred in the selected direction.

\section{CONCLUSION}

The following conclusions can be drawn from the experimental work carried out

1. Arduino based channel temperature logging system provides a low-cost solution for temperature estimation at different points during welding.

2. The maximum peak temperature of about 800 degree Centigrade was recorded by the thermocouple just below weld center line.

3. The weld temperature of about 200 Degree Centigrade was recorded by thermocouple placed farthest from the centerline.

4. The cooling rates estimated from temperature-time graph can help in determining the metallurgical changes at the point of interest.

\section{REFERENCES}

[1] Gery, D. Long, H. and Maropoulos, P. "Effects of Welding Speed, Energy Input and Heat Source Distribution on Temperature Variations in Butt Joint Welding”. Journal of Materials Processing Technology, No. 167, pp. 393-401, Elsevier, 2005.

[2] Hooda, A., Dhingra, A. and Sharma, S. "Optimization of MIG Welding Process Parameters to Predict Maximum Yield Strength in AISI 1040" IJMERR, No. 3pp. 203-213, Elsevier 2012.
[3] Vemanaboina, H., Akella, S. and Buddu, R.K., "Welding Process Simulation Model for Temperature and Residual Stress Analysis" $3^{\text {rd }}$ International Conference on Materials Processing and Characterization, No. 6, pp. 1539 - 1546, Elsevier, 2014. 